$$
\begin{aligned}
& M-20 \\
& 021260
\end{aligned}
$$

NASA Technical Memorandum 107414

AIAA-96-2961

\title{
Power Electronics for a Miniaturized Arcjet
}

\author{
Luis R. Piñero
}

Lewis Research Center

Cleveland, Ohio

and

Glen E. Bowers

Gilcrest Electric

Brook Park, Ohio

Prepared for the

32nd Joint Propulsion Conference and Exhibit cosponsored by AIAA, ASME, SAE, and ASEE

Lake Buena Vista, Florida, July 1-3, 1996

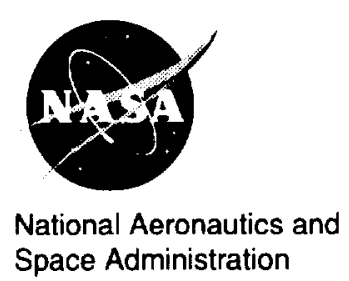





\title{
POWER ELECTRONICS FOR A MINIATURIZED ARCJET
}

\author{
Luis R. Piñero* \\ National Aeronautics and Space Administration \\ Lewis Research Center \\ Cleveland, Ohio 44135 \\ Glen E. Bowerst \\ Gilcrest Electric \\ 3000 Aerospace Parkway \\ Brook Park, Ohio 44142
}

\begin{abstract}
A $0.3 \mathrm{~kW}$ Power Processing Unit (PPU) was designed, tested on resistive loads, and then integrated with a miniaturized arcjet. The main goal of the design was to minimize size and mass while maintaining reasonable efficiency. In order to obtain the desired reductions in mass, simple topologies and control methods were considered. The PPU design incorporates a $50 \mathrm{kHz}$, current-mode-control, pulse-widthmodulated (PWM), push-pull topology. An input voltage of $28 \pm 4 \mathrm{~V}$ was chosen for compatibility with typical unregulated low-voltage busses anticipated for smallsats. An efficiency of 0.90 under nominal operating conditions was obtained. The component mass of the PPU was $0.475 \mathrm{~kg}$ and could be improved by optimization of the output filter design. The estimated mass for a flight PPU based on this design is less than a kilogram.
\end{abstract}

\section{Introduction}

Since the 1980's, various arcjet systems have been developed for power levels from 1 to $30 \mathrm{~kW} \cdot 1-2 \mathrm{~A}$ $1.8 \mathrm{~kW}$ hydrazine arcjet system with a specific impulse of $500 \mathrm{~s}$ is currently operational on Lockheed Martin 7000 Series spacecraft. ${ }^{1}$ A 2.2 kW, 600 second specific impulse system is currently baselined for North-South Stationkeeping on a new GEO comsat series. ${ }^{3}$ A $0.5 \mathrm{~kW}$ arcjet system is being developed and tested under a joint NASA / industry program for both primary and auxiliary propulsion. 4-5 Potential applications for this system are stationkeeping, orbit insertion, and drag make-up for communication satellites and primary propulsion for near-Earth science spacecraft.

NASA's current plans for Earth-space and planetary missions require the miniaturization of spacecraft. Spacecraft subsystems must be small, light-weight, and efficient due to the limited power and thermal control capacity inherent in small spacecraft design. A high performance low power arcjet system may benefit multiple missions by reducing the on-board propellant requirements compared to resistojet, chemical, or cold gas systems while retaining a relatively simple propellant system architecture.

To support NASA's initiative to reduce spacecraft size, a miniaturized arcjet system is being evaluated. The miniature arcjet was designed to operate using either ammonia or hydrazine propellant at a nominal power level of $0.3 \mathrm{~kW}$. This thruster has demonstrated throttleability to $0.2 \mathrm{~kW} .6$ Recent studies have concentrated on improving miniature arcjet performance. ${ }^{7}$

As part of the low-power arcjet development effort, a $0.3 \mathrm{~kW}$ breadboard power processing unit (PPU) was designed with the goal of minimizing size and mass while maintaining reasonable efficiency. Power electronics for low-power arcjets have been developed in the past based on both a full-bridge topology and current-mode pulse-width-modulated (PWM) control. 8 This breadboard was optimized for efficiency but not for minimum mass and complexity. In order to obtain the desired reductions in mass and size in the miniaturized arcjet effort, simple topologies and control methods were considered. An input voltage range of $24-32 \mathrm{~V}$ was selected for

*Electrical Engineer, On-Board Propulsion Branch.

†Electronics Systems Mechanic. 
compatibility with the unregulated low voltage power busses anticipated for smallsats.

This paper documents the design process and performance characteristics of the PPU, and presents the results of resistive load tests and integration tests with a miniature arcjet.

\section{Desien Considerations}

\section{Spacecraft / PPU Interface}

Typical smallsats are anticipated to have unregulated low voltage power busses. To maintain compatibility, a nominal input voltage of $28 \pm 4 \mathrm{~V}$ was chosen for this design. Also, input-output isolation was desired to conform with single point grounding schemes. Even though this is a low power application, it is important to obtain the highest possible efficiency to minimize impact on the spacecraft's power and thermal control systems. The efficiency goal for this design was approximately 0.90 which corresponds to $0.030 \mathrm{~kW}$ of losses at a typical $0.3 \mathrm{~kW}$ output level. An EMI filter was not designed because it was not within the scope of this program.

\section{Thruster / PPU Interface}

Typical voltage-current characteristics of the miniaturized arcjet for both simulated hydrazine and ammonia propellant have been reported. 6 Ammonia performance was substantially higher than hydrazine and slightly higher arc voltages for the same arc current and flowrate setpoints were observed. Previous data show that typical arc voltages for the flowrate range of interest and a power level of approximately $0.3 \mathrm{~kW}$ are within 130 to $170 \mathrm{~V}$. The PPU was designed with a nominal open circuit voltage of $200 \mathrm{~V}$ so that it could operate the thruster using either propellant and could provide some contingency for higher voltage operation. A reliable pulsed ignition technique for hydrazine arcjets has been demonstrated in previous work and was also used in this design. ${ }^{8-12}$ Initial values for the ignition pulse of approximately $1.9 \mathrm{kV}$ and $12 \mu$ s were chosen for this design based on past experience. This may need optimization but modifications are not expected to impact the PPU design greatly. A maximum steady state current ripple requirement of 15 to 20 percent was used based on previous work. ${ }^{8-11}$

\section{Topology}

\section{Design}

The design goal was to minimize PPU mass and complexity while maintaining a reasonable efficiency. An isolated topology was also required to simplify integration of an arcjet system to a spacecraft by being compatible with single point grounding schemes. Previous arcjet PPU designs have used a phase shifted full-bridge topology. 8 This topology was not chosen for this effort because it requires a complex power stage including four power switches, isolation for the driver circuits, and additional circuitry for gate drive phase shift. A flyback topology with an additional winding to reset the power transformer (also known as forward topology) was also considered. This topology requires only one power switch without driver isolation. The main disadvantages are that it is unstable during open circuit operation and the power transformer core has a very low utilization factor because it is only excited in one direction. Finally, push-pull topology was evaluated and chosen for this design. The push-pull has been successfully used with higher power arcjets in previous work. ${ }^{9}$ It requires two switches and a bifilar primary winding as shown in the PPU schematic in Figure 1. One issue associated with this particular design was the fabrication of the power transformer. The expected high primary current requires a considerable amount of wire to minimize conduction losses in the transformer. As a result, special winding techniques to reduce leakage inductance and improve magnetic coupling are difficult to implement in the small core selected to reduce the mass of the PPU. Currentmode-control pulse-width-modulation was used on this design to avoid staircase saturation in the power transformer and for primary current limit.

\section{Transformer}

The power transformer was wound on a toroidal 3F3 ferrite core. Ferrite materials yield a lower mass for the same cross sectional area compared to tape wound cores. Also, ferrite cores have lower core losses compared to many metal cores. A switching frequency of $50 \mathrm{kHz}$ and a maximum magnetic flux density of $0.27 \mathrm{~T}$ were chosen to reduce transformer size. Both windings were made of multiple strands of 24 AWG magnet wire to reduce losses due to skin effect. The maximum calculated core and conduction losses for this transformer at nominal conditions were $3.1 \mathrm{~W}$ and $0.6 \mathrm{~W}$, respectively. 


\section{Output Filter}

A maximum output current ripple of 15 to 20 percent was used as in previous PPU designs. ${ }^{8-11}$ Because 2.0 A of output current was specified for this design, a large inductor is required to meet the ripple specification. Using a switching frequency of $50 \mathrm{kHz}$ on the PPU reduces the time the output inductor has to provide current to the arcjet while running at a certain duty cycle. This, in turn, reduces the inductance needed to meet the ripple specification. An amorphous metallic alloy $\mathrm{C}$-core was chosen because its high saturation flux allowed both number of turns required and core size to be reduced. The output inductor also has an integral start winding which is part of the arcjet ignition circuit. Details on this ignition technique are presented elsewhere. 12 An advantage of this technique is that the pulse characteristics can be easily tailored by minor changes in the ignition circuit to meet system requirements.

\section{Physical Characteristics}

Minimizing the mass and size of the PPU was the most important requirement of this design. The total component mass of the breadboard PPU as seen in the photograph shown in Figure 2, is $0.475 \mathrm{~kg}$. The total weight is $0.95 \mathrm{~kg}$. The heaviest component in the PPU is the output inductor $(0.175 \mathrm{~kg})$. The inductor core was oversized due to limited core availability, but its weight and size could be considerably reduced by using a smaller core. Another heavy component is the power transformer which weights approximately $0.100 \mathrm{~kg}$. This transformer design compares favorably with sizes of other designs and its window utilization is very good. Based on the breadboard weight and the anticipated improvements, it is estimated that a flight PPU could weigh less than a kilogram.

\section{Performance}

\section{Output Characteristics}

The PPU output characteristics were evaluated via operations on a resistive load. The voltage-current characteristics of the PPU, at an output current of 2.0 $A$ and for input voltages of 24,28 , and $32 \mathrm{~V}$, are shown in Figure 3. The open circuit voltage is between 185 and $245 \mathrm{~V}$ over the input voltage range.
Table 1 shows performance data for various input and load conditions on the PPU. Both load and line regulation are better than $1 \%$ over the range of load conditions and input voltages.

The arcjet ignition circuit is also powered by the input bus. A family of ignition pulses from the PPU is shown in Figure 4. The magnitude and width of the ignitions pulse is a function of the input voltage. For input voltages of 24,28 , and $32 \mathrm{~V}$, the pulse magnitudes were $1.6,1.8$, and $2.1 \mathrm{kV}$,respectively, with a duration of approximately $12 \mu \mathrm{s}$. These result in pulse energies of $14.1,18.3$, and $25.3 \mathrm{~mJ}$, respectively.

\section{Efficiency}

The efficiency of the power supply was measured using digital multimeters to measure the input and output voltages and currents while operating the power supply on a resistive load. Table 1 shows efficiency data for various conditions. The efficiency varied between 0.88 and 0.92 for typical load values over the input voltage range of interest. The nominal operating condition was an input of $28 \mathrm{~V}$, an output current of $2.0 \mathrm{~A}$, and a load 60 to $70 \Omega$. The measured efficiency at this nominal point was 0.90 . Notice that all efficiency numbers quoted herein include housekeeping power. It was observed that the efficiency was higher when the PPU was running at lower input voltage or when it was heavily loaded. This was anticipated because at these conditions the power stage operates at higher duty cycles which reduces the required energy storage in the output filter. Calculated power losses for various components at nominal conditions are shown in Table 2. The major contributions are due to switching and conduction losses in the power stage, core losses in the power transformer and the output inductor, conduction losses in the output rectifiers, and losses in the snubbers due to the leakage inductance of the power transformer.

Efficiency could be improved by using larger cores for the magnetic components to reduce core magnetic flux densities. Also, the switching losses could be reduced by reducing the switching frequency. But, since the most important goal of this design was to minimize mass and volume, neither of these options were implemented. The power transformer windings were not optimized but it is anticipated that better winding techniques could help reduce the leakage inductance which would result in reduce power losses in the snubbers. 


\section{Thruster Integration}

The PPU was integrated with a prototype miniaturized arcjet which is described in detail elsewhere. 6-7 The arcjet consisted of a single piece anode $\left(\mathrm{W} / 2 \% \mathrm{ThO}_{2}\right)$, brazed to the rear-half of the thruster. The nozzle had divergent and convergent half-angles of $15^{\circ}$ and $30^{\circ}$, respectively. The constrictor had a diameter of $0.25 \mathrm{~mm}$ and a length of $0.13 \mathrm{~mm}$. The cathode was also made of $\mathrm{W} / 2 \% \mathrm{ThO}_{2}$ with a diameter of $1.6 \mathrm{~mm}$ and a $30^{\circ}$ half-angle conical tip. The arc gap was set to 0.41 $\mathrm{mm}$. The total weight of this thruster was $0.18 \mathrm{~kg}$. Testing was done in a facility described elsewhere. 13 A stoichiometric mixture with a $3: 1$ ratio of hydrogen and nitrogen was used to simulate ammonia. The propellant flowrate for the test was $15.0 \mathrm{mg} / \mathrm{s}$.

\section{Thruster Ienition}

The arcjet testing was started at $28 \mathrm{~V}$ input voltage to the PPU. At this input voltage, the ignition pulses had a magnitude of $1.9 \mathrm{kV}$, a duration of approximately $12 \mu \mathrm{s}$, and an energy of approximately $18.3 \mathrm{~mJ}$. The miniaturized thruster was reliably started throughout the whole input voltage range. A typical breakdown of the miniaturized arcjet is shown in Figure 5. Prior to the ignition pulse, the PPU open circuit voltage was approximately $215 \mathrm{~V}$. As can be seen from the figure, the arcjet broke down close to the peak of the ignition pulse. The current overshot to approximately $2.7 \mathrm{~A}$ after ignition and then ramped down to the nominal $2.0 \mathrm{~A}$ setpoint in less than $2.0 \mathrm{~ms}$.

\section{Steady State Operation}

During the integration test, the arcjet never stabilized. Large voltage variation and oscillations in the plume were observed. It was presumed that this was caused by a cathode/anode alignment problem. For a 2.0 A current, the arc voltage fluctuated around $140 \pm 10 \mathrm{~V}$ which corresponds to a power level of approximately $0.280 \mathrm{~kW}$. While it was not possible to resolve this problem in time to impact this report, the fact that the PPU was able to maintain this operating mode was very encouraging as it represents a much harder operating condition than the steady state

Arc voltage and current waveforms for a nominal operating point are shown in Figure 6 . The current ripple is approximately $200 \mathrm{~mA}$ which corresponds to 10.0 percent ripple at a $2.0 \mathrm{~A}$ output current. The arcjet was operated for approximately 2.0 hours without incident.

\section{Conclusions}

A $50 \mathrm{kHz}$, push-pull, current-mode PWM power processor for miniaturized arcjets was successfully developed. It was tested on resistive loads at power levels between 0.150 to $0.350 \mathrm{~kW}$ at input voltages of 24 to $32 \mathrm{~V}$. Line and load regulation was better than 1 percent and efficiency ranged from 0.88 to 0.92 for typical operating points. This design was based on previous $1-\mathbf{k W}$ class PPU designs and also included an integral start winding on the output inductor for arcjet ignition. The component mass of the PPU was $0.475 \mathrm{~kg}$ and it could be further improved by optimization of the output inductor design. It is presumed that a flight PPU using this design could weigh less than a kilogram.

The PPU successfully operated a miniaturized arcjet despite the fact that the device was running poorly due to assembly issues. It was tested for approximately 2.0 hours at a flowrate of $15.0 \mathrm{mg} / \mathrm{s}$ and a power level of $0.280 \mathrm{~kW}$. Multiple starts were successful at various input voltages to the PPU.

\section{References}

1. Smith, R.D., et al., "Qualification of a $1.8 \mathrm{~kW}$ Hydrazine Arcjet System," Proceedings of the 23rd International Electric Propulsion Conference, Sept. 1993, pp. 93-107.

2. Wong, S.P. and Britt, E.J., "Non-Isolated $30 \mathrm{~kW}$ Class Arcjet PCU," NASA CR NAS3-25609, March 1994.

3. McLean, C.H., et al., "Life Demonstration of a 600-Second Mission Average Arcjet," AIAA Paper 94-2866, June 1994. 
4. Curran, F.M. and Sarmiento, C.J., "Low Power Arcjet Performance," AIAA Paper 90-2578, July 1990 (also NASA TM 103280).

5. Curran, F.M. and Haag, T.W., "Extended Life and Performance Test of a Low-Power Arcjet, " $J$. of Spacecraft and Rockets, Vol. 29, No. 4, July-Aug. 1992, pp. 444-452.

6. Sankovic, J.M. and Jacobson, D.T., "Performance of a Miniaturized Arcjet," AIAA Paper 95-2822, July 1995.

7. Sankovic, J.M. and Hopkins, J.B., "Miniaturized Arcjet Performance Improvement," AIAA Paper 962962, July 1996.

8. Hamley, J.A. and Hill, G.M., "Power Electronics for a Low Power Arcjets," AIAA Paper 91-191, June 1991 (also NASA TM 104459).
9. Gruber, R.P., "Power Electronics for a 1-Kilowatt Arcjet Thruster," AIAA Paper 86-1507, June 1986 (also NASA TM 87340).

10. Hamley, J.A., et al., " $10 \mathrm{~kW}$ Power Electronics for Hydrogen Arcjets," NASA TM 105614, February 1992.

11. Gruber, R.P., et al., "5-KW Arcjet Power Electronics," AIAA Paper 89-2725, July 1989 (also NASA TM 102108).

12. Sarmiento, C.J. and Gruber, R.P., "Low Power Arcjet Thruster Pulse Ignition," AIAA Paper 87-1951, June 1987 (also NASA TM 100123).

13. Sankovic, J.M. and Berns, D.H., "Performance of a Low-Power Subsonic-Arc-Attachment Arcjet Thruster," AIAA Paper 93-1898, June 1993 (also NASA TM 106204). 


\begin{tabular}{|c|c|c|c|c|c|c|}
\hline Vin (V) & Iin (A) & Pin (W) & Vout (V) & Iout (A) & Pout (W) & Eff (\%) \\
\hline 32.00 & 9.40 & 300.8 & 133.9 & 2.00 & 267.8 & 89.03 \\
32.00 & 11.90 & 380.8 & 173.8 & 2.00 & 347.6 & 91.28 \\
28.00 & 10.61 & 297.08 & 133.70 & 2.00 & 267.40 & 90.01 \\
28.00 & 13.44 & 376.32 & 173.80 & 2.00 & 347.60 & 92.37 \\
24.00 & 12.26 & 294.24 & 133.70 & 2.00 & 267.40 & 90.88 \\
32.00 & 7.27 & 232.64 & 117.20 & 1.75 & 205.10 & 88.16 \\
32.00 & 9.25 & 296.00 & 152.60 & 1.75 & 267.05 & 90.22 \\
28.00 & 8.25 & 231.00 & 117.30 & 1.75 & 205.28 & 88.86 \\
28.00 & 10.50 & 294.00 & 152.80 & 1.75 & 267.40 & 90.95 \\
24.00 & 9.48 & 227.52 & 117.00 & 1.75 & 204.75 & 89.99 \\
24.00 & 12.03 & 288.72 & 152.20 & 1.75 & 266.35 & 92.25 \\
\hline
\end{tabular}

Table 1. Miniaturized arcjet PPU efficiency data for various input and load conditions.

\begin{tabular}{|c|c|}
\hline \multicolumn{2}{|l|}{ Conduction Losses: } \\
\hline $\begin{array}{l}\text { Transformer: } \\
\text { Output Inductor: } \\
\text { MOSFETs: } \\
\text { Rectifiers: }\end{array}$ & $\begin{array}{l}0.6 \mathrm{~W} \\
0.4 \mathrm{~W} \\
2.2 \mathrm{~W} \\
4.0 \mathrm{~W}\end{array}$ \\
\hline \multicolumn{2}{|l|}{ Core Losses: } \\
\hline $\begin{array}{l}\text { Transformer: } \\
\text { Output Inductor: }\end{array}$ & $\begin{array}{l}3.1 \mathrm{~W} \\
2.7 \mathrm{~W}\end{array}$ \\
\hline Switching Losses: & $4.5 \mathrm{~W}$ \\
\hline Housekeeping: & $2.5 \mathrm{~W}$ \\
\hline Snubbers: & $5.5 \mathrm{~W}$ \\
\hline Other: & $4.2 \mathrm{~W}$ \\
\hline Total at $267.4 \mathrm{~W}$ output: & $29.7 \mathrm{~W}$ \\
\hline
\end{tabular}

Table 2. Measured and calculated power losses at nominal conditions. 


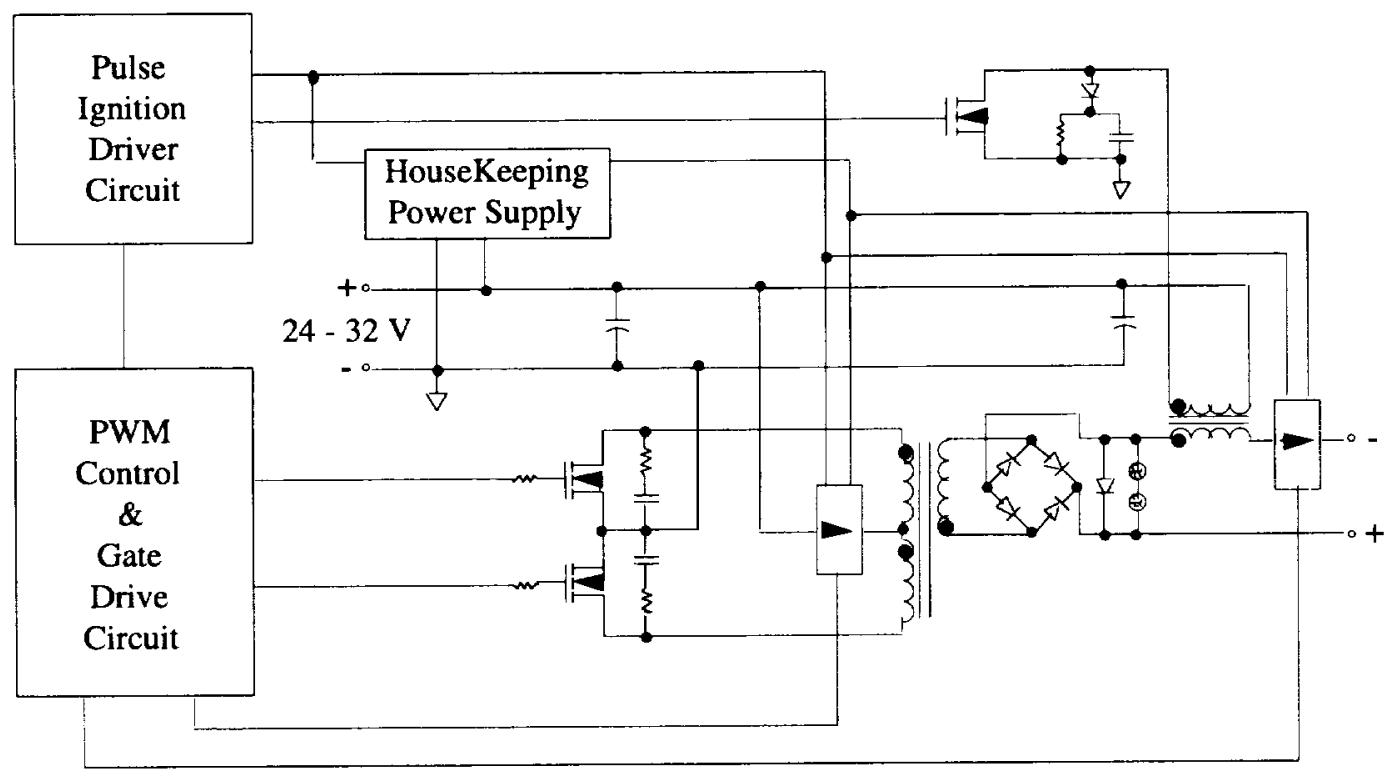

Figure 1. Miniaturized arcjet PPU schematic.

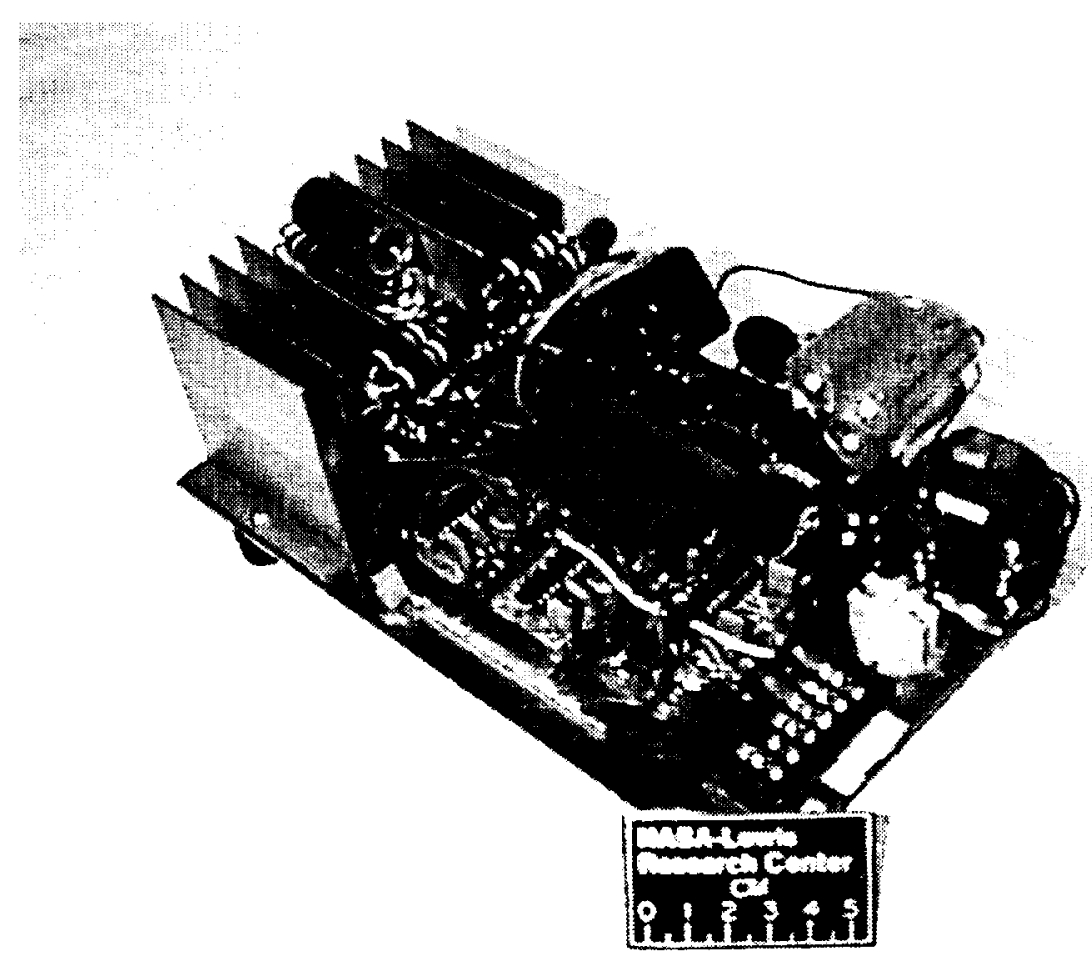

Figure 2. Minitaturized arcjet PPU breadboard. 


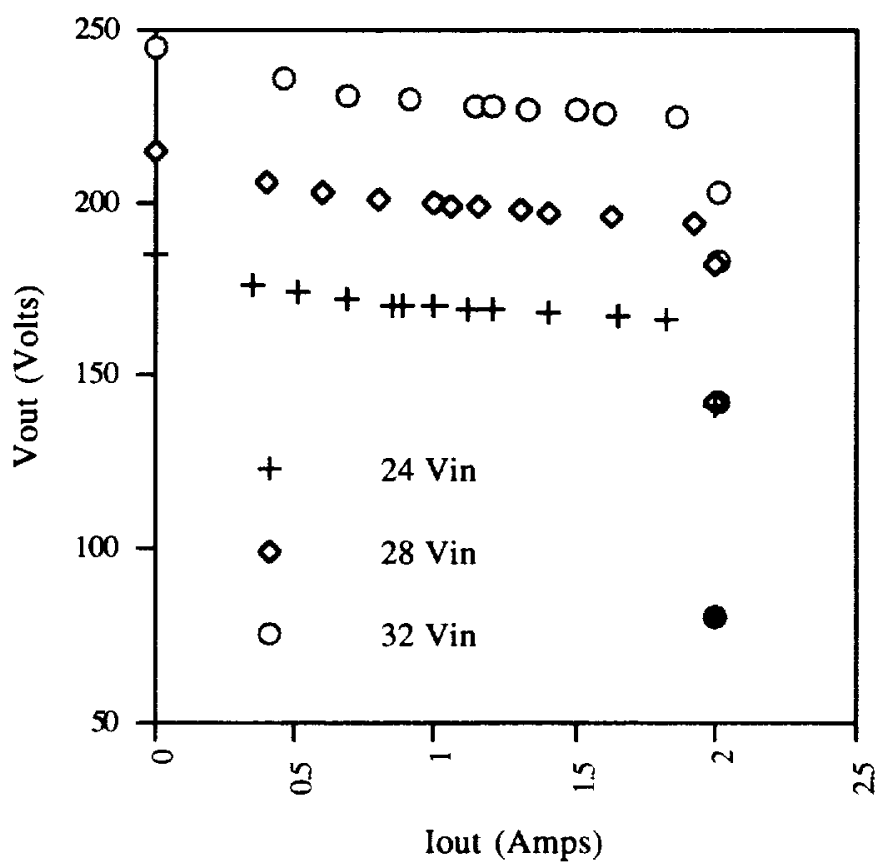

Figure 3. Miniaturized arcjet PPU output characteristics at 2.0 A output current and various input voltages.

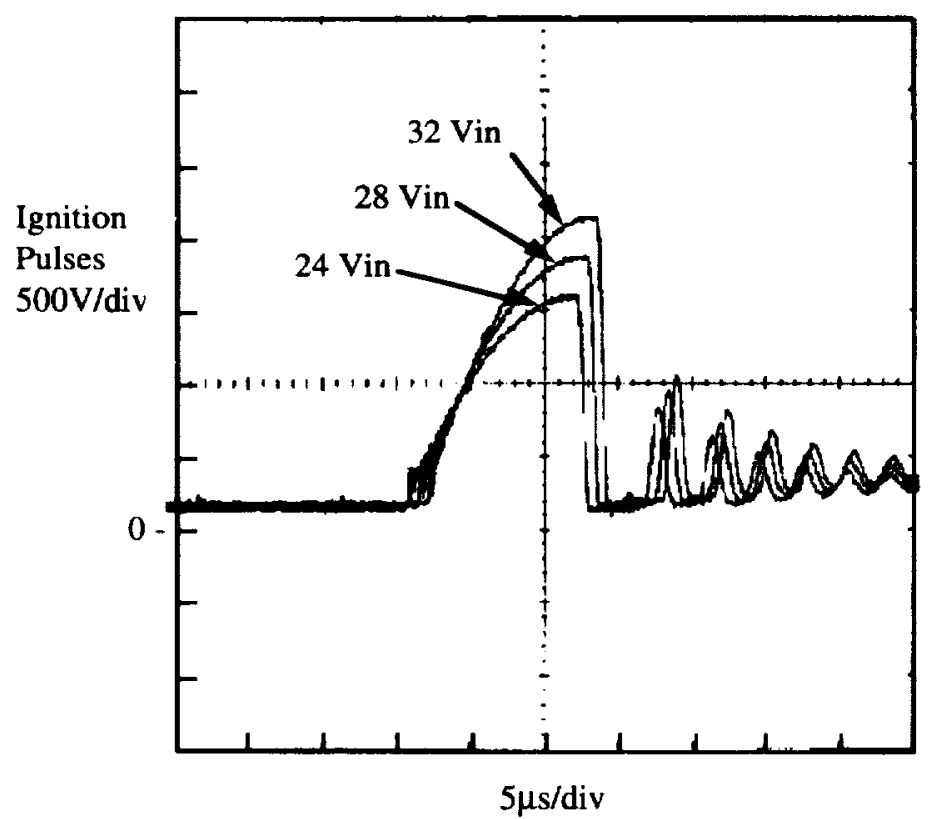

Figure 4. Family of ignition pulses at various input voltages. 


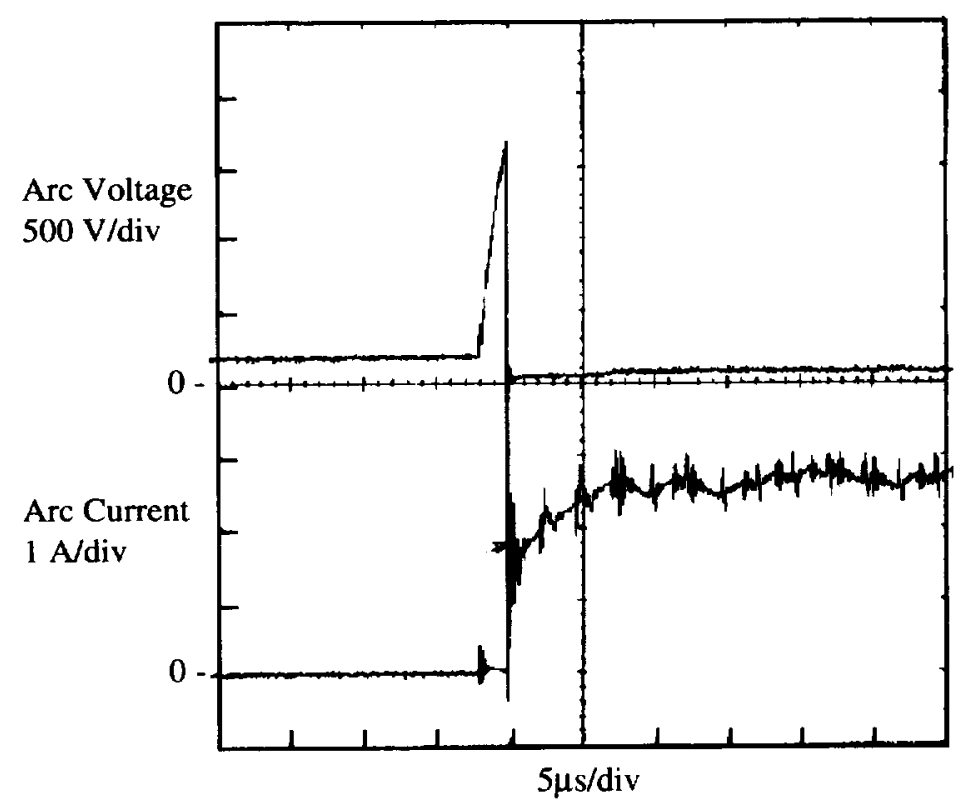

Figure 5. Voltage and current waveforms for arcjet ignition.

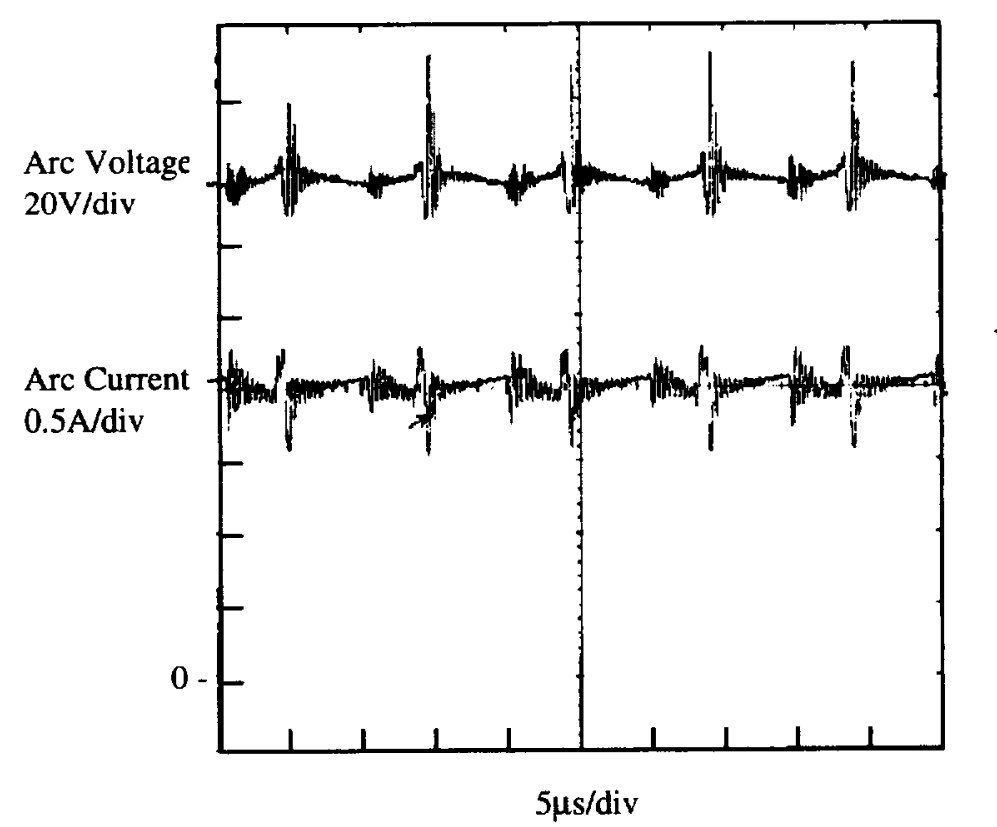

Figure 6. Output voltage and current waveforms for steady state operation of a miniaturized arcjet. 
Public reporting burden for this collection of information is estimated to average 1 hour per response, including the time for reviewing instructions, searching existing data sources, gathering and maintaining the data needed, and completing and reviewing the collection of information. Send comments regarding this burden estimate or any other aspect of this collection of information, including suggestions for reducing this burden, to Washington Headquarters Services, Directorate for Information Operations and Reponts, 1215 Jefferson Davis Highway, Sutte 1204, Arlington, VA 22202-4302, and to the Ottice of Management and Budget, Paperwork Peduction Project (0704-0188), Washington, DC 20503.

\begin{tabular}{|l|c|c}
\hline 1. AGENCY USE ONLY (Leave blank) & $\begin{array}{c}\text { 2. REPORT DATE } \\
\text { April } 1997\end{array}$ & $\begin{array}{c}\text { 3. REPOFT TYPE AND DATES COVERED } \\
\text { Technical Memorandum }\end{array}$ \\
\hline
\end{tabular}

\section{TITLE AND SUBTITLE}

Power Electronics for a Miniaturized Arcjet

6. AUTHOR(S)

Luis R. Piñero and Glen E. Bowers

7. PERFORMING ORGANIZATION NAME(S) AND ADDRESS(ES)

National Aeronautics and Space Administration

Lewis Research Center

Cleveland, Ohio 44135-3191

9. SPONSORING/MONITORING AGENCY NAME(S) AND ADDRESS(ES)

National Aeronautics and Space Administration

Washington, DC 20546-0001
WU-233-1B-1B

8. PERFoRMING ORGANIZATION REPORT NUMBER

E-10650

10. SPONSORINGMONITORING AGENCY REPORT NUMBER

NASA TM-107414

AIAA-96-2961

\section{SUPPLEMENTARY NOTES}

Prepared for the 32nd Joint Propulsion Conference and Exhibit cosponsored by AIAA, ASME, SAE, and ASEE, Lake Buena Vista, Florida, July 1-3, 1996. Luis R. Piñero, NASA Lewis Research Center, and Glen E. Bowers, Gilcrest Electric, 3000 Aerospace Parkway, Brook Park, Ohio 44142. Responsible person, Luis R. Piñero, organization code 5330, (216) $433-7428$.

12a. DISTRIBUTION/AVAILABILITY STATEMENT 12b. DISTRIBUTION CODE

Unclassified - Unlimited

Subject Category 20

This publication is available from the NASA Center for AeroSpace Information, (301) 621-0390.

13. ABSTRACT (Maximum 200 words)

A $0.3 \mathrm{~kW}$ Power Processing Unit (PPU) was designed, tested on resistive loads, and then integrated with a miniaturized arcjet. The main goal of the design was to minimize size and mass while maintaining reasonable efficiency. In order to obtain the desired reductions in mass, simple topologies and control methods were considered. The PPU design incorporates a $50 \mathrm{kHz}$, current-mode-control, pulse-width-modulated (PWM), push-pull topology. An input voltage of $28 \pm 4 \mathrm{~V}$ was chosen for compatibility with typical unregulated low voltage busses anticipated for smallsats. An efficiency of 0.90 under nominal operating conditions was obtained. The component mass of the PPU was $0.475 \mathrm{~kg}$ and could be improved by optimization of the output filter design. The estimated mass for a flight PPU based on this design is less than a kilogram.

14. SUBJECT TERMS

15. NUMBER OF PAGES

Electric propulsion; Arcjet; Power processing

17. SECURITY CLASSIFICATION OF REPORT

Unclassified
18. SECURITY CLASSIFICATION OF THIS PAGE Unclassified
19. SECURITY CLASSIFICATION OF ABSTRACT Unclassified 